\title{
SUSTAINABLE NEIGHBORHOOD IN THE CONTEXT OF PRIMARY SCHOOL STUDENTS' ENERGY LITERACY IN AN URBAN AREA: FIELD STUDY
}

\author{
Dimitrios Poimenidis ${ }^{1 *}$, Vasileios Papavasileiou ${ }^{2}$ \\ ${ }^{1}$ Dr, University of the Aegean, Greece, poimenidis@aegean.gr \\ ${ }^{2}$ Assoc. Prof. Dr., University of the Aegean, Greece, vpapavasileiou@rhodes.aegean.gr \\ ${ }^{*}$ Corresponding author
}

\begin{abstract}
Complex contemporary social, economic, and environmental problems create challenges in terms of urban environmental quality, infrastructure, transport and energy. Concurrently, considerable pressures are exerted, resulting in serious environmental consequences. "Sustainable cities" are the cities we must create and leave a legacy for the future generations. The design of public spaces, roads, sidewalks, squares, cycle lanes, waste collection and waste management are fundamental issues in the context of sustainable urban development, for which, if local governments implement policies for sustainable urban planning and design and if there is funding, accessible technology, and education, it will enhance citizens' quality of life, provide comfort, increase accessibility, and significantly minimize the amount of energy consumed while reducing the human impact on the environment. However, most cities are already facing many problems such as urban environmental degradation, traffic congestion, inadequate urban infrastructure, and lack of public services, like waste management. Hence, Urban Environmental Management is the key target of sustainability in terms of ensuring quality management. Respectively, informing citizens, educating them, and strengthening their environmental literacy, notably the energy one, is the main pillar for the reduction or elimination of the issues affecting the urban quality of life. The children's active participation in an exploratory study, through education in relevant issues, provides the opportunity for them to be informed, learn, and develop their critical thinking. Hence, a two-month work plan was implemented in October and November 2020, which involved students in active and experiential ways of learning, both theoretically and in the field of study. After concluding the teaching approaches, the fourth graders of primary school were divided in 18 groups and carried out a week-long research. They observed and reported issues related to the quality of their neighborhood structure in combination with the processes and services of the town municipality. The study results initially outline the children's developing cognitive ability to critically approach the urban issues, to adopt models of sustainable development related to energy. The research highlights the lack of parking infrastructure, the adequate width of sidewalks, the absence of adequate road signs and pedestrian crossings in neighborhoods, the existence of not only an adequate number of waste containers but also the need to replace them systematically, as well as the citizens' rational attitude concerning waste disposal. Furthermore, it seems that it is necessary for the municipal public services to implement additional training programs for the cleaning service staff. Additionally, questions concerning the limited number of recreational parks for children and the need for better management and maintenance of the existing ones were noted. Moreover, the need arises for the implementation of a general campaign regarding safety precautions by the local government to improve driver behavior in accordance with the Highway Code. Lastly, exploring these issues maximized the children's active participation in the field of study by making them into critical observers, strong critical thinkers, and informed citizens of tomorrow who currently understand the actions and social practices that take place in the urban realm.
\end{abstract}

Keywords: neighborhood, sustainability, urban management, energy literacy 


\section{INTRODUCTION}

Modern cities comprise densely populated housing systems in which many critical issues arise. Today more than $50 \%$ of people live in cities and this is expected to increase and reach $80 \%$ by 2050 (UNEP, 2012). The population rise and the operations carried out in urban areas pose serious ecological challenges (Cepeliauskaite \& Stasiskiene, 2019). Nevertheless, experts argue that dense housing can reduce energy needs, but this is not the key to sustainability as specific factors need to be considered such as neighborhood characteristics, public transport, services, land use and type of housing (Yang \& O'Neill, 2014). As a consequence, the diversity of issues cities face is reflected in their initial design, implementation and the creation and management of infrastructure that ensure to a certain extent the proper functioning, safety and health of citizens. In contrast, medium density residential zones offer better solutions embedded in their architectural design.

Many of the issues in the urban fabric depend on long-term energy choice strategies, local conditions, urban planning, the city's characteristics, and technology-related issues (Zaręba et al., 2017). In particular, proper urban planning, the rational use of local resources as well as the ones treated as waste, the use of renewable energy sources, local energy production and food production can be considered dimensions of local self-sufficiency and inflow (and secondary) resources (EEA, 2015).

The issue of urban planning standards is the fundamental tool for the local government to support the longterm planning and vision of the city (UNHABITAT, 2013) and to prevent future potential malfunctions and needs (or issues that may arise) which can be aggravated due to urbanism.

Urban design is a unique tool to avoid negative effects in an urban area, as the sustainable development of cities can only occur through viable urban plans and specifications (EEA, 2015). The matter is mainly left to the elected representatives of the local government and central government at the level of urban planning and decisions making regarding city infrastructure. Nevertheless, there are questions that concern the behavior of the average citizen and the way he/she behaves and acts in his/her daily life.

Thus, special attention should be paid to the concepts of sustainability and sustainable urban development in order to raise awareness on the production and use of resources in areas related to the residential and industrial sector, transport, trade or the citizens' entertainment (Trindade et al., 2017). The trends that are formed according to the modern way of life further show that there is a need to educate residents about the environment in which they inhabit (Urbanc \& Fridl, 2012).

\section{THE URBAN CITIZEN}

The citizens' friendly or unfriendly attitude towards not only the natural environment but also the structured one specifies the positive or negative effects that are caused and affect in various ways the inhabitants, usually changing in a negative way the living conditions. Nevertheless, the strategies and solutions regarding the implementation of an ecological city will have the effect of reducing the demand and use of energy resources, thus minimizing the impact on the environment (Bibri, 2020). The issue of high-density housing worsens the comfort of the residence and presumably deprives residents of green spaces as they are a key element of improving the quality of life (Kotulla et al., 2019). Similarly, the issue of energy consumption exacerbates the waste of fossil fuels as they continue to sustain to a large extent both electricity production and vehicle movement through conventional means of transport (Martins et al., 2019). Concurrently, greenhouse gas emissions continue to rise with devastating consequences for the environment and health. Furthermore, the issue of citizens reducing overconsumption is another major point as the ecosystems are at risk of collapsing meaning rapidly losing their structure and function with dramatic changes to their size or extent, or the species that comprise them. The over-consumption of resources and goods creates environmental, social, cultural and economic pressures and at the same time waste disposal affects the environment as hazardous substances are disposed of instead of simply been recycled (Ribić et al., 2017). Waste production can be decreased by waste collection and recycling so as to become resources for exploitation (Lee et al., 2020). However, recycling itself as a practice is only one part of the solution to the problem without being the solution itself, although it encounters the waste problem in the long run (Norman, 2020; Bartl, 2014). Moreover, it induces significant social, economic and mainly environmental benefits concerning saving resources and energy, while the level of improving the city's sustainability is evident from the degree to which it is implemented (Grosse \& Mainguy, 2010). The best way to counteract waste disposal 
effectively and be environmentally friendly is not to create rubbish from the beginning (EPA, n.d.). Namely, the most important issue is the non-purchase and non-use of goods, in the sense of restricting consumption, that are often not necessary but they are aligned with the idea that the people's wellbeing and happiness depend fundamentally on obtaining consumer goods material possessions; a notion that has prevailed in the last decades.

Additionally, the absence of green spaces and recreational parks, the small and narrow roads, the nonexistence of sidewalks or sidewalks unsuitable for the citizens, the lack of adequate parking spaces and urban planning standards for proper traffic control procedures are issues that the urban citizen is facing nowadays.

All things considered, it is necessary to cultivate and educate a properly informed citizen who is stimulated and as an active member of society and a critical thinker can engage in all those individual and collective behaviors and practices to reduce or eliminate difficulties. Concurrently, a city dweller needs to be capable of monitoring, judging and being active against situations of deterioration, provocation, or indifference in order to resolve them, putting himself primarily at the center of an environmentally responsible behavior (Papavasileiou et al., 2017; Papavasileiou, 2015). Educating citizens in terms of sustainable management raises another crucial issue according to which the combination of urban inadequacy in terms of basic city infrastructure and state processes at the level of local municipalities, and the deficit or unfriendly environmental behavior of citizens counteract the ecological footprint and maximize the waste of resources and energy. Moreover, cities are, directly or indirectly, an important generator of greenhouse gases, which they significantly aggravate (Caparros - Midwood et al., 2015). In contrast, education plays an important role in the context of education on the environment and sustainability (Papavasileiou, 2015).

\section{METHODOLOGY}

In order to form the perceptions and strengthen the knowledge and the skills of critical approach to key environmental issues in the urban fabric of the town of Rhodes, a two-month work plan was implemented (in October and November 2020), in the context of the investigation of children's energy literacy after didactic approaches have been conducted, which involved students in active and experiential ways of learning, both theoretically and in the field of study. After concluding the teaching approaches, the fourth graders of primary school were divided in 18 groups depending on the residential area in the wider school zone and carried out a week-long research through observation, record keeping, and a later analysis and report of the data collected. The aim was to highlight the quality of the structured environment in combination with processes and services of the town municipality and the issues students face in their living areas.

The research issues emerged through the didactic interventions and highlight the most common points of the residents in the nearby area. The study was conducted with a structured questionnaire (Cohen et al., 2013) and recorded the issues focusing on waste management, the existence of green and recreational areas, parking lots and the suitability of roads and sidewalks. These questions, among other things, are directly or indirectly related to citizens' energy literacy. Thus, it is essential children acquire a critical approach, observation skills, knowledge, to form new perceptions and to influence or reshape their personalities through their active participation in the study and clarification of these key points. The study findings were recorded in frequency tables and deductions were made. The results are presented descriptively below.

\section{STUDY FINDINGS}

The presence of waste bins, their neatness and appearance are important elements related to the citizens' public health and safety. Regarding the existing condition of the waste bins, it is apparent from the observations that they are mainly in a moderate condition $(72.2 \%)$ or an awfully bad one $(22.2 \%)$ whereas there are few statements for their excellent condition (5.6\%). There seems to be a serious issue at this point. When asked if trash containers are washed immediately after waste collection by a specialized vehicle of the municipality, $88.9 \%$ of the children noticed that the bins are not washed so as not to cause health problems and unpleasant odors whereas only $11.1 \%$ of them noted that the bins were washed immediately after they were emptied.

When asked if waste containers have a foot pedal, it seems that $77.8 \%$ of them do not have one or it is damaged, while only $22.2 \%$ of the bins have one that functions properly. This indicates that in several cases $(44.45 \%)$ the citizens must manually open the lid by hand to dispose of their garbage or use the foot medal without touching the trash can $(55.55 \%)$.

Waste collection at the proper time significantly ensures public health. The municipal garbage trucks collect the rubbish on daily basis in every neighborhood and mainly in the early morning hours (72.25\%), 
occasionally in the afternoon (22.2\%) and sporadically (5.55\%) at noon, so that they are not full in the morning. Before garbage collection, the surrounding area is generally without waste thrown out of the bins $(88.9 \%)$ while there are few reports of garbage disposed of out of the waste containers $(11.1 \%)$. This means that the citizens throw garbage out correctly in the bins and its quantity does not create problems on the storage and the capacity of the trash containers. In addition, the children noted that there are not any large and bulky objects around the trash bins to a large extent $(88.9 \%)$ except in a few cases (11.1\%). In consequence, citizens display basic environmental behavior without undermining the issue of waste disposal and possibly the amount of garbage they produce.

However, the children reported that after waste collection they noticed fallen rubbish out of the bins to a limited extent $(49.9 \%$ of little rubbish or not at all), to a great extent $(27.8 \%)$ and to a greater extent $(11.1 \%)$; only $11.1 \%$ of the statements indicate that no fallen waste is observed out of waste containers. The children's records highlight the issue of guidance and training of the employees of the Municipality's Public Cleanliness Department.

In addition, regarding waste collection from shift to shift, the waste containers are often filled $(77.8 \%)$ or half filled with litter $(22.2 \%)$. This indicates the possibility of more frequent visits from rubbish trucks and refuses collectors to gather the rubbish. Another important issue seems to be the street litter bins which, as the children note, do not exist (100\%) at some distance on main roads to serve passers-by while there are only large disposal containers. In smaller vertical roads there are some public garbage cans (16.6\%) but in most roads $(83.4 \%)$ there are still no litter bins. Additionally, it seems that these litter baskets are not regularly cleaned by the cleaning service staff and as a result they are usually filled with litter (100\%).

Regarding sidewalks, many students $(55.55 \%)$ recorded that there are sidewalks on both sides of the road in the neighborhood streets, while the rest of them noted that pavements do not exist $(45.45 \%)$. Concerning the streets where pavements do exist, $72.25 \%$ of the children state that their width is sufficient for two people to be able to cross simultaneously, while the cases are limited respecting pedestrians not being able to walk on the sidewalks $(27.75 \%)$. Concurrently, street litter bins do not obstruct passers-by walking on pavements $(100 \%)$. However, there is an issue regarding sidewalk accessibility for people with disabilities as it seems there is limited provision $(27.25 \%)$ for suitable pavements that are navigable for someone using a mobility device (e.g., a wheelchair), while in most cases (72.25\%) there is no planning for accessible walkways.

Furthermore, the study indicates there are not any trees planted on sidewalks that prevent pedestrians from walking on them $(83.35 \%)$, while in some cases $(16.65 \%)$ trees are planted on pavements. The ideal situation would be if trees did not obstruct pedestrians from walking on sidewalks and enhanced the children's neighborhood aesthetic. Moreover, keeping sidewalks clean is especially important; thus, a cleaning program is implemented to a large extent (83.35\%) and, as a result, pavements are kept unpolluted apart from a few cases (16.65\%). Concurrently, there is adequate lighting for sidewalks as there is night lighting (83.35\%), which functions correctly and to a large extent $(77.8 \%)$, although many children report that it is not sufficient as additional street illumination is needed (88.9\%). This statement may be precarious depending on other factors such as children's fear of night.

Most children (100\%) report that there is no provision regarding vehicle parking areas. This is a serious urban planning issue. Nevertheless, the vehicles that are illegally parked on the sidewalks are significantly limited $(11.1 \%)$. $88.9 \%$ of the citizens do not engage in this illegal practice which makes pedestrian mobility difficult when implemented. Moreover, prohibitory traffic signs are minimal $(22.2 \%)$, while in most cases they are non-existent $(72.15 \%)$. Only $5.55 \%$ of the children $(5.55 \%)$ did not state the issue.

In most cases the children's residential areas have adequate safety signage (66.7\%) while on several occasions it does not exist and must be placed (33.3\%). The number of pedestrian crossings is insufficient in the children's neighborhoods (83.3\%) while it is considered sufficient to a limited degree depending on the instance (16.7\%). Moreover, in cases where it is reported that there are pedestrian crossings, children report that drivers usually do not comply with the Traffic Rules and Regulations and do not give way to pedestrians $(100 \%)$. These are profoundly serious issues to educate citizens. Respectively, they record a serious lack of traffic lights $(88.9 \%)$.

Regarding the existence of green zones within the children's residential areas, it seems that they are extremely limited (83.3\% do not exist), while there are few statements of their presence (16.7\%). Respectively, concerning the existing public parks, their condition is poor, since $50 \%$ of them have adequate lighting, waste bins and are kept clean. In addition, many public parks are inadequate concerning the lower levels of tree cover or remnant vegetation cover they contain (50\%). However, all children report that there are no dangerous points within parks that are related to possible injuries. 


\section{DISCUSSION AND CONCLUSSIONS}

The study of crucial questions regarding the students' residential areas with a critical approach from the children's perspective is an important educational advantage to form perceptions, views and acquire knowledge; elements that shape individual responsibility and subsequent adult behavior. After integrated didactic interventions, active investigation and record keeping highlight the existing issues related to urban planning, daily processes, and energy issues in terms of direct and integrated (gray) energy in the children's living environment; issues that are based on the axes of investigation of the specific research approach. The survey was conducted in the children's 18 local neighborhoods and highlights with accuracy an empirical evaluation of the current situation. The results of the children's field-based study findings are representative and based on the actual local conditions.

The existence of a sufficient number of waste containers relieves the problem of disposing of and transferring rubbish to disposal facilities, although Waste Management Programs should be implemented through direct or indirect recycling (EPA, 2020; Gencer, 2015). Nevertheless, most public waste bins' poor condition raises issues regarding the citizens' health and safety. These issues concern their improper cleaning and washing after waste collection by a specialized municipal vehicle. Moreover, they involve the waste bins' absence of foot pedal, which compels citizens to manually open the lid by hand to dispose of their garbage.

The regular and timely litter collection is a proper functional process of the municipal waste collection services, while the citizens respect the disposal operations and do not leave litter or bulky objects out of the bins. They seem to act in terms of protecting their aesthetics and personal health by having a responsible attitude towards proper waste disposal and garbage collection. Nevertheless, litter bins are almost filled with rubbish on several occasions, and this signals the need to provide training through adult education programs regarding waste management, as several household rubbish such as food waste could be composted to provide fertilizers (Klinglmair \& Thomsen, 2020), while other recyclable materials such as paper, metals and glass could be disposed of more intensively in recycling bins, thus reducing the environmental and energy costs. However, although recycling is of great significance, it is the third pillar of the problem, as the reduction and reuse of materials are of paramount importance (Gencer, 2015) and thus reduce the gray or embedded energy consumed during the life cycle of a product (Woods et al., 2010). An issue, however, arises concerning rubbish left after litter collection due to the garbage collectors' negligence. Thus, the Municipality's Public Cleanliness Department should take measures to train its cleaning service staff properly and effectively. Moreover, the absence of bulky waste indicates the citizens' sensible behavior of not discarding bulky items in the streets or next to the waste containers.

Road and sidewalk specifications are an important issue for safety, facilitation, and rational energy management. In the children's living areas, the existence of few sidewalks, deficiencies regarding ramps for Disabled Access, the limited number of pedestrian crossings and the absence of urban tree canopies are issues that municipal public services must timely address. Undoubtedly, the adequate current sidewalk pavement width observed for facilitating pedestrians, being well-maintained and the adequate street lighting are fundamental elements for safe, accessible, well-maintained and versatile sidewalks (Shaaban, 2019), although the children stated that they would expect brighter street lights to illuminate public spaces.

The shortage of parking spaces in the city is a cause for serious problems that lead to poor traffic management, traffic congestion and traffic accidents, energy waste and illegal parking (Parmar et al., 2020; Mannini et al., 2017). Furthermore, the lack of adequate traffic signs and traffic lights has a negative effect on the citizens' safety (Hatfield et al., 2006) and energy wastefulness. Consequently, it appears that drivers do not give way to pedestrians crossing the road causing annoyance (Papadimitriou et al., 2012). This issue must be addressed both technically by the municipal public services and educationally by schools, through traffic education to teach the public about traffic safety.

Regarding the existence of green zones within the children's residential areas, it seems that they are extremely limited while there are issues in the current public parks and green spaces regarding cleanliness, lighting, tree cover and vegetation cover, so that they are more inviting and attractive and contribute to the wellbeing of the city citizens. Nevertheless, a key point concerning the children's answers is that they did not notice or report the presence of dangerous places or neglected parks that make them unsafe.

The children's research approach clarified a wide range of issues, it made them active, it engaged them in critical thinking and offered an experiential educational method that was developed exceptionally, leading the children to empirical recording and learning, while after the study, the results were sent to the municipal government. 


\section{REFERENCE LIST}

Bartl, A. (2014). Moving from recycling to waste prevention: a review of barriers and enables. Waste Management \& Research, 32(9), 3-18.

Bibri, S. E. (2020). The eco-city and its core environmental dimension of sustainability: green energy technologies and their integration with data-driven smart solutions. Energy Informatics, 3(4).

Caparros - Midwood, D., Barr, S. \& Dawson, R. (2015). Optimised spatial planning to meet long term urban sustainability objectives. Computers, Environment and Urban Systems, 54,154-164.

Cepeliauskaite, G. \& Stasiskiene, Z. (2019). The Framework of the Principles of Sustainable Urban Ecosystems Development and Functioning. Sustainability, 12 (720). DOI:10.3390/su12020720

Cohen, L., Manion, L. \& Morrison, K. (2013). Research Methods in Education. London: Routledge.

EPA, US. (2020). Recycling Economic Information (REI) Report. Accessed on 13 April 2021. URL: https://www.epa.gov/sites/production/files/2020-11/documents/rei report 508 compliant.pdf

EPA. (n.d.). Reducing and Reusing Basics. Accessed on 04 April 2021. URL: https://www.epa.gov/recycle/reducing-and-reusing-basics\#benefits

European Environment Agency (EEA). (2015). Urban sustainability issues - Resource-efficient cities: good practice. EEA Technical report/No 24/2015.

Gencer, G. Y. (2015). Mystery of Recycling: Glass and Aluminum Examples. In U. Akkucuk (Ed), Handbook of Research on Waste Management Techniques for Sustainability, Chapter 9, pp. 172-191. DOI: 10.4018/978-1-4666-9723-2.ch009

Grosse, F. \& Mainguy, G. (2010). Is recycling "part of the solution"? The role of recycling in an expanding society and a world of finite resources. S.A.P.I.EN.S [Online] 3(1). Accessed on 03 April 2021. URL: http://journals.openedition.org/sapiens/906

Hatfield, J., Fernandes, R., Job, r. S. \& Smith, K. (2007). Misunderstanding of right-of-way rules at various pedestrian crossing types: Observational study and survey. Accident Analysis \& Prevention, 39(4), 833-42. DOI:10.1016/j.aap.2006.12.005

Klinglmair, M. \& Thomsen, M. (2020). Using Food Waste in Organic Fertilizer: Modelling Biogenic Carbon Sequestration with Associated Nutrient and Micropollutant Loads. Sustainability, 12, 7399. DOI: $10.3390 /$ su12187399

Kotulla, T., Denstadli, J. M., Oust, A. \& Beusker, E. (2019). What Does It Take to Make the Compact City Liveable for Wider Groups? Identifying Key Neighbourhood and Dwelling Features. Sustainability, 11, 3480. DOI:10.3390/su11123480

Lee, R. P., Meyer, B., Huang, Q. \& Voss, R. (2020). Sustainable waste management for zero waste cities in China: potential, challenges and opportunities. Clean Energy, 4(3), 169-201, https://doi.org/10.1093/ce/zkaa013

Martins, F., Felgueiras, C., Smitkova, M. \& Caetano, N. (2019). Analysis of Fossil Fuel Energy Consumption and Environmental Impacts in European Countries. Energies, 12, 964; DOI:10.3390/en12060964

Norman, D. (2020). Recycling: A poor solution to the wrong problem: An essay in two parts. Accessed 5 April 2020 from https://jnd.org/recycling-a-poor-solution-to-the-wrong-problem/

Papadimitriou, E., Theofilatos, A., Yannis, G., Sardi, G-M. \& Freeman, P. J. R. (2012). Road Safety Attitudes and Perceptions of Pedestrians in Europe. Procedia - Social and Behavioral Sciences, 48, 2490 2500.

Papavasileiou, V. (2015). Sustainable Development and Education: A multidimensional relationship. Athens: Diadrasi. (in Greek)

Papavasileiou, V., Nikolaou, E., Xanthacou, Y. Papadomarkakis, I., Matzanos, D. \& Kaila, M. (2017). Student preschool teachers' views about the pedagogical context of sustainable kindergarten. Proceedings of INTCESS 2017 4th International Conference on Education and Social Sciences. Istanbul, Turkey, 6-8 
February, 2017.

Parmar, J., Das, P. \& Dave, M. D. (2020). Study on demand and characteristics of parking system in urban areas: A review. Journal of Traffic and Transportation Engineering (English Edition), 7(1), 111-124.

Ribić, B., Voća, N. \& llakovac, B. (2017). Concept of sustainable waste management in the city of Zagreb: Towards the implementation of circular economy approach. Journal of the Air \& Waste Management Association, 67(2), 241-259.

Shaaban, K. (2019). Assessing Sidewalk and Corridor Walkability in Developing Countries. Sustainability, 11, 3865. DOI: $10.3390 /$ su11143865

Trindade, E. P., Hinnig, M. P. F., da Costa, E. M., Sabatini - Marques, J., Bastos, R. C. \& Yigitcanlar, T. (2017). Sustainable development of smart cities: a systematic review of the literature. Journal of Open Innovation: Technology, Market, and Complexity, 3(11). DOI 10.1186/s40852-017-0063-

UNEP. (2012). Sustainable, Resource Efficient Cities -Making it Happen!. ISBN: 978-92-807-3270-2. DTI/1538/PA.

UNHABITAT. (2013). Urban planning for city leaders. United Nations Human Settlements Programme (UNHabitat). HS Number: HS/090/12E. ISBN Number: 978-92-1-132505-8

Urbanc, M. \& Fridl, J. (2012). Education for active citizenship in spatial-planning processes: from teacher to student. Geografski vestnik, 84(1), 227-235.

Woods, J., Williams, A., Hughes, K. J., Black, M. \& Murphy, R. (2010). Energy and the food system. Philosophical Transportation of The Royal Society, B, 365, 2991-3006. DOI:10.1098/rstb.2010.0172

Yang, Y. \& O'Neill, K. (2014). Understanding factors affecting people's attitudes toward living in compact and mixed-use environments: A case study of a New Urbanist project in Eugene, Oregon, USA. Journal of Urbanism: International Research on Placemaking and Urban Sustainability, 7, 1-22.

Zaręba, A., Krzemińska, A. \& Łach, J. (2017). Energy sustainable cities. From eco villages, eco districts towards zero carbon cities. E3S Web of Conferences 22, 00199. DOI: 10.1051/e3sconf/20172200199. 